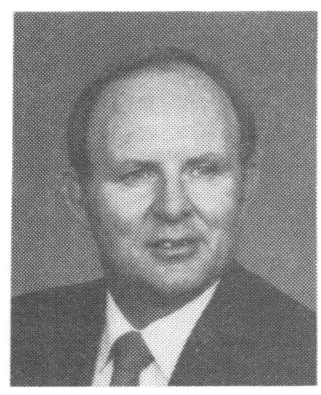

Editorial

Jack D. Gaskill, Editor

Three Down-Two to Go

On June 30 of this year I will have served as Editor of Optical Engineering for three years, and, as you might have gathered from the title of this editorial, I have agreed to stay on for two more years-until June 30 , 1990. I have decided to step down and let someone else take over at that time and have so informed the Chair of the Publications Committee, Hank Carter.

After a total of five years in the position I think it will be time to move on to other things and to hand over the reins to someone else. Being Editor has been a great experience, and I have seen a side of professional life that I would otherwise have missed, but some aspects of the job are starting to become just a bit tedious.

To illustrate, the editorial you are now reading is the thirty-third I have written for the journal. I am finding that, as time goes on, I seem to have less and less to say about more and more-or is it more and more to say about less and less-and I still have twenty-four editorials to go. Perhaps an infusion of new blood will yield some new directions for the journal and some refreshing editorials for you long-suffering editorial readers. I have also discovered that the job has certain good news/bad news aspects: the good news is that the contributed manuscripts seem to arrive faster than I can get them sent out for review, and the bad news is that I can't seem to get them sent out for review as fast as they arrive. I can never even get caught up, let alone get ahead.

There is also some good news/bad news associated with the special issues: the good news is that many more manuscripts are promised than are needed, and the bad news is that the number of them that actually get submitted is sometimes far fewer than the number promised. More good news is that very few of the authors and referees anticipate any problems in meeting the various deadlines, and more bad news is that these deadlines are often missed by several weeks or months. On occasion the bad news has been so bad that we were forced to cancel an entire special issue. As they say-when it rains, it pours; and, as I indicated above, I think the time to hand these rains over to someone else is just about two years away.

One last item: a year ago, as I was writing my editorial for the June 1987 issue, I was concerned about the approach of an eventful date-May 31st. My score on this date in recent years is as follows: 1985, hit by a truck while riding a bicycle; 1986, married while standing in a church; 1987, nothing (which really made me paranoid); and 1988, yet to be determined (which makes me even more paranoid). I am definitely not superstitious, but this morning-Friday, May 13, 1988-I broke a spoke while powering my bicycle up a $1 \%$ grade. Realizing that the 13th is a transposition of the 31st, I wonder if something incredibly ominous lurks ahead. It's enough to make me want to consult an astrologer and have my horrorscope read; after all, even paranoids have reasons to worry.

\section{Future Special Issue \\ Call for Papers}

February 1989

\section{Polarization Considerations for Optical Systems}

\section{Guest Editor}

Russell A. Chipman

Center for Applied Optics

University of Alabama in Huntsville

Huntsville, AL 35899

205/895-6030

FAX 205/895-6618

The February 1989 special issue of Optical Engineering will be devoted to polarization considerations for optical systems. Recent optical system concepts in optical computing, optical data storage, laser radar, and many other applications rely on polarized light for their operation. These systems have necessitated the development of new methods for the design, analysis, and testing of polarization-critical systems. This special issue will cover the polarization analysis of optical systems, polarization properties of optical elements, sources and detectors, and polarization-based optical system concepts.

Special emphasis will be placed on methods for optical design with polarized light, including polarization ray tracing, polarization aberration theory, and other methods to simulate the effects of crystals, thin films, optical fibers, and other polarizing elements on the propagation of polarized light through optical systems. Topics of interest include polarization modulators, ultralow polarization lenses, and polarizing beam splitters. Polarizing optical system concepts of interest include laser radar, optical signal processors and computers, optical data storage, fiber optic sensors, ellipsometers, and spectropolarimeters.

Authors are encouraged to submit manuscripts on any of the above topics for inclusion in the special issue. Manuscripts for consideration should be sent to the Guest Editor before Aug. 15, 1988.

(See p. 460 for complete Editorial Schedule.) 